\title{
SGC-CK2-1: the first selective chemical probe for the pleiotropic ki- nase CK2
}

\author{
Carrow Wells, $\perp^{\perp, \neq,\urcorner}$ David H. Drewry, ${ }^{\perp, \neq,\urcorner,}$ Julie E. Pickett, ${ }^{\ddagger,\urcorner}$ Alison D. Axtman ${ }^{*, \neq,\urcorner}$ \\ ${ }^{\ddagger}$ Structural Genomics Consortium (SGC), UNC Eshelman School of Pharmacy, University of North Carolina at Chapel Hill \\ (UNC-CH), Chapel Hill, NC, 27599, USA \\ ᄀDivision of Chemical Biology and Medicinal Chemistry, UNC Eshelman School of Pharmacy, UNC-CH, Chapel Hill, NC, \\ 27599, USA
}

KEYWORDS: kinase, IDG, CK2, CSNK2A1, CSNK2A2, dark kinase, small molecule, nanoBRET, chemical probe

\begin{abstract}
Building upon a wealth of published knowledge surrounding the pyrazolopyrimidine scaffold, we designed a small library around the most selective small molecule CK2 inhibitors reported. Through extensive evaluation of this library we identified inhibitor 24 (SGC-CK2-1) as a potent, selective, and cell-active CK2 chemical probe. Remarkably, despite years of research pointing to CK2 as a key driver in cancer, our probe did not elicit an antiproliferative phenotype in cell lines tested. While many publications have attempted to characterize CK2 function, CK2 biology is complex and a high-quality chemical tool like SGC-CK2-1 will aid in connecting CK2 functions to phenotypes.
\end{abstract}

Protein phosphorylation is one of the most common and important post-translational modifications. ${ }^{1}$ Protein kinases catalyze this reaction, phosphorylating a specific substrate, and causing a conformational change that affects protein function. ${ }^{2}$ One protein kinase, CK2 (casein kinase 2), phosphorylates more than 300 proteins. ${ }^{3}$ Via genetic and biochemical studies in a variety of experimental models, CK2 has been found to be both constitutively active and ubiquitously expressed, making it

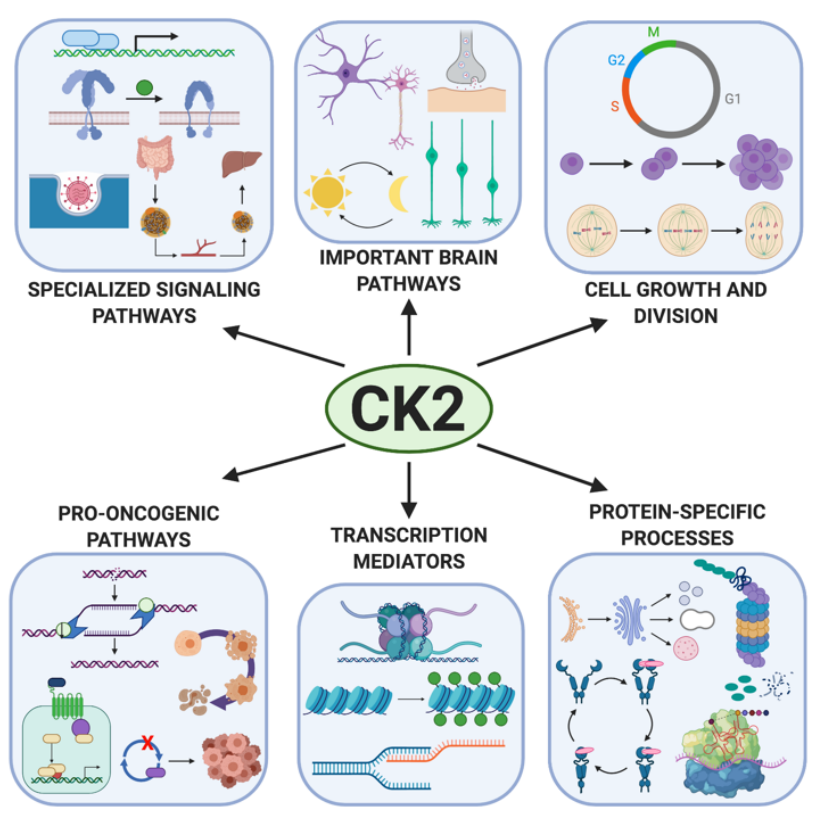

Figure 2. Summary of CK2 mediated pathways. important in many biological processes (Figure 1, Table S1)..$^{3-6}$ CK2 exists as a tetrameric complex made up of two catalytic subunits, CSNK2A1 (CK2 2 ) and CSNK2A2 (CK2 $\left.\alpha^{\prime}\right)$, and two regulatory subunits, CSNK2B (CK2 $\beta){ }^{7}$ Being able to selectively inhibit $\mathrm{CK} 2$ would prove useful in understanding its role in a multitude of pathways ranging from cell survival and proliferation to inflammation. ${ }^{6}$<smiles>Brc1c(Br)c(Br)c2[nH]nnc2c1Br</smiles><smiles>O=C(O)c1ccc2c(c1)nc(Nc1cccc(Cl)c1)c1ccncc12</smiles>

CX-4945<smiles>O=c1c(O)c(-c2ccc(O)c(O)c2)oc2cc(O)ccc12</smiles>

Fisetin
Figure 1. Literature CK2 inhibitors.

Although CK2 biology has been well-studied, with almost 750 references in PubMed, truly selective and potent inhibitors of $\mathrm{CK} 2$ are limited. The first reported compounds that bound to $\mathrm{CK} 2$ varied from benzotriazoles (e.g. - TBB) to natural product-like flavonoids (Figure 2). TBB was first published as a CK2 inhibitor in 1995 and demonstrated modest selectivity for CK2 over CK1 (casein kinase 1). ${ }^{8}$ Later it was evaluated against a panel of $33^{9}$ and $70^{10}$ kinases and, while maintaining reasonable selectivity, it did inhibit several other kinases with $>90 \%$ inhibition at a screening concentration of $10 \mu \mathrm{M}$ (DYRK1A, DYRK2, DYRK3, HIPK2, and PIM1-3). In 2010, the compound CX4945 was published, which has since become the most commonly employed CK2 inhibitor. ${ }^{11}$ Given its antiproliferative activity in several different cancer cell lines, this inhibitor has been advanced and is currently being evaluated in clinical trials for 
several oncology indications, basal cell carcinoma (NCT03897036), multiple myeloma (NCT01199718), cholangiocarcinoma (NCT02128282), breast cancer (NCT00891280) and medulloblastoma (NCT03904862). ${ }^{12}$ Despite being fairly narrow spectrum, CX-4945 does inhibit other kinases below $100 \mathrm{nM}$ (DAPK3, FLT3, TBK1, CLK3, HIPK3, PIM1, and CDK1). ${ }^{12}$ The off-target activities of this inhibitor could provide confounding results when trying to attribute target to function to phenotype.

Given both the biological importance of this target and lack of selective inhibitors, we identified the need for a CK2 chemical probe to enable accurate elucidation of the biological effects of inhibition. Three recent publications from scientists at AstraZeneca disclose a series of pyrazolopyrimidines with nanomolar (nM) potency for CK2. They further evaluate this series for both mechanistic and phenotypic endpoints, including pAKT levels and antiproliferative activity. ${ }^{13-16}$ While the compounds are potent, even one of their best compounds (17) also has offtargets (HIPK1-4, DAPK1-3, DYRK2, and BMPR1B) that may confound interpretation of biological results. ${ }^{15}$ Due to its narrow kinome profile as well as potency, we started our CK2 probe project utilizing this promising scaffold.

Based on published pyrazolopyrimidines targeting CK2 and associated biochemical data, we opted to resynthesize a subset of the published molecules and expand into new chemical space by designing and preparing an additional 6 analogs not previously described in these papers. Table 1 shows the structures and corresponding CK2 enzymatic activity for our subset of previously exemplified molecules that we resynthesized for further characterization.

Table 1. Reported CSNK2A inhibitors and biochemical activity. ${ }^{13-16}$
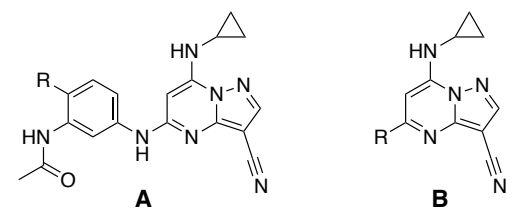

$\begin{array}{cccc}\text { Cmpd } & \text { Scaffold } & \begin{array}{c}\text { Reported CK2 } \\ \text { IC } 50 \text { (nM) }\end{array} \\ 17 & \text { A } & <3 \\ 29 & \text { A } & 9 \\ 31 & \text { A } & 10\end{array}$

Three of these compounds $(\mathbf{1 7}, \mathbf{2 2}, \mathbf{2 9})$ had been previously reported to have narrow selectivity profiles when screened at Ambit/DiscoverX in panels of 324 (29) or 402 (17 and 22) kinases. The remaining three compounds are close structural analogs with potent enzymatic activity, but for which limited selectivity data had been reported. ${ }^{13-16}$ Figure 3 shows the compounds we designed based upon surveying the literature for structures and corresponding data. Structure-activity relationships were developed, and compounds designed that incorporated minor structural changes $(\mathbf{1 8}, \mathbf{2 4}, \mathbf{2 6})$ and some slightly larger structural perturbations $(19,20,27)$. While it was anticipated that the minor structural changes would result in compounds of broadly similar potency and selectivity to their progenitors, the others were designed to probe the pocket and determine which interactions were favorable and what changes might lead to enhanced selectivity.

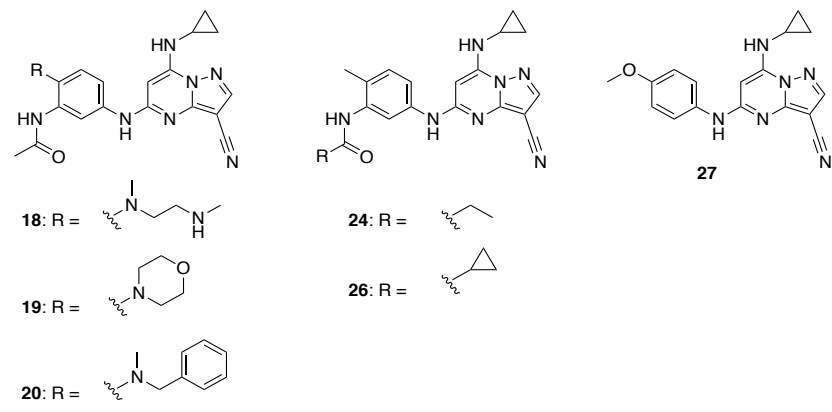

Figure 3. Synthetic CK2 targeting library.

All analogs were prepared using convergent chemistry and, where possible, utilizing previously reported synthetic routes. ${ }^{13}$ ${ }^{15}$ Key transformations, including nucleophilic aromatic substitution and Buchwald-Hartwig amination, allowed preparation of all analogs. Detailed routes are included in the Supporting Information (Schemes S1-S3).

Upon preparation of the analogs shown in Table 1 and Figure 3 , we assessed the cellular penetrance and target engagement of all compounds using the CSNK2A1 and CSNK2A2 nanoBRET assays in HEK-293 cells. Given the high sequence homology of the active sites of CSNK2A1 and CSNK2A2, we did not anticipate preferential binding to one versus the other. ${ }^{17}$ The nanoBRET assay relies upon bioluminescence resonance energy transfer (BRET) between CSNK2A1-Nluc or CSNK2A2-Nluc and a tracer with a red-shifted fluorophore appended. Our analogs, which compete with the tracer for binding to the active site, were introduced in a dose-dependent manner and BRET was plotted versus concentration, allowing us to calculate a target engagement $\mathrm{IC}_{50}$ value. ${ }^{18}$ In parallel, the compound set was sent to Eurofins DiscoverX to be profiled against 403 wild type human kinases using their scanMAX platform to characterize the kinome-wide selectivity. Table 2 summarizes our findings related to the cellular potency and kinome-wide selectivity of the compounds we prepared.

From the entire set of compounds, 4 of our 6 novel pyrazolopyrimidines from Figure 3 (20, 24, 26, and 27) exhibited the best kinome-wide selectivity (Table 2 ). Of note, our compounds are significantly more selective than the most frequently used CK2 inhibitor in the literature, CX-4945. CX-4945 has an $S_{10}(1 \mu \mathrm{M})=0.069$ with 28 kinases $>90 \% \mathrm{I}$ and compound 24 , for example, has an $S_{10}(1 \mu \mathrm{M})=0.007$ with only 3 kinases $>90 \%$ I. The entire series proved to be active in the CSNK2A1 and CSNK2A2 cellular target engagement assays with several single digit nanomolar inhibitors (Figure S3). As expected, no difference in potency was observed between the two CSNK2A 
Table 2. Potency and selectivity of CK2-targeting pyrazolopyrimidines.

\begin{tabular}{|c|c|c|c|c|c|c|c|c|}
\hline Cmpd & $S_{10}(1 \mu M)$ & $\begin{array}{c}\text { \# kinases } \\
>90 \% \mathrm{I} \text { at } \\
1 \mu \mathrm{M}\end{array}$ & $\begin{array}{c}\text { CSNK2A1 } \\
\text { NB IC } 50 \\
(\mathbf{n M})\end{array}$ & $\begin{array}{c}\text { CSNK2A2 } \\
\text { NB IC } 50 \\
(\mathbf{n M})\end{array}$ & $\begin{array}{l}\text { Wild type kinases } \\
>90 \% \mathrm{I} \text { at } 1 \mu \mathrm{M} \\
(\% \mathrm{I})\end{array}$ & $\begin{array}{c}{\text { Enzymatic } \text { IC }_{50}}_{\text {values }(\mathbf{n M})}\end{array}$ & $\begin{array}{c}\text { Wild type } \\
\text { kinases }>35 \% \mathrm{I} \\
\text { at } 1 \mu \mathrm{M}(\% \mathrm{I})\end{array}$ & $\begin{array}{c}\text { Off-target } \mathrm{IC}_{50} \text { or } \\
\text { enzymatic assay } \\
\text { values }(\mathrm{nM})\end{array}$ \\
\hline 17 & 0.042 & 17 & 5.3 & 4.4 & Figure S2 & NT & & \\
\hline 15 & 0.02 & 8 & 2.7 & 1.3 & Figure S2 & NT & & \\
\hline 16 & 0.012 & 5 & 15 & 7.6 & Figure S2 & NT & & \\
\hline 22 & 0.032 & 13 & 3.2 & 1.8 & Figure S2 & NT & & \\
\hline 29 & 0.015 & 6 & 11 & 3.9 & Figure S2 & $\mathbf{N T}$ & & \\
\hline 31 & 0.027 & 11 & 94 & 20 & Figure S2 & NT & & \\
\hline 18 & 0.025 & 10 & 3.3 & 2.6 & Figure S2 & NT & & \\
\hline 19 & 0.025 & 10 & 67 & 15 & Figure S2 & $\mathbf{N T}$ & & \\
\hline 20 & 0.005 & 2 & 280 & 130 & $\begin{array}{l}\text { CSNK2A2 (100) } \\
\text { CSNK2A1 }(96.7)\end{array}$ & $\begin{array}{l}\text { CSNK2A2: } 94 \\
\text { CSNK2A1: } 91\end{array}$ & & \\
\hline 24 & 0.007 & 3 & 36 & 16 & $\begin{array}{c}\text { CSNK2A2 (100) } \\
\text { DRAK1 (100) } \\
\text { CSNK2A1 (99.5) }\end{array}$ & $\begin{array}{c}\text { CSNK2A2: } 2.3 \\
\text { DRAK1: > 10,000 } \\
\text { CSNK2A1: } 4.2\end{array}$ & $\begin{array}{l}\text { DYRK2 (86) } \\
\text { PLK4 (77) } \\
\text { HIPK2 (74) } \\
\text { MEK5 (72) } \\
\text { HIPK1 (68) } \\
\text { HIPK3 (66) }\end{array}$ & $\begin{array}{c}\text { DYRK2: } 440 \\
\text { PLK4: }>10000 \\
\text { HIPK2: } 3400 \\
\text { MEK5: } 0 \% \text { I at } 1 \mu M \\
\text { HIPK1: } 3700 \\
\text { HIPK3:8100 }\end{array}$ \\
\hline 26 & 0.002 & 1 & 7700 & 2700 & CSNK2A2 (100) & CSNK2A2: 120 & $\begin{array}{c}\text { CSNK2A1 (80) } \\
\text { SGK1 (68) } \\
\text { SGK3 (67) }\end{array}$ & $\begin{array}{l}\text { CSNK2A1: } 150 \\
\text { SGK1: >10000 } \\
\text { SGK3: >10000 }\end{array}$ \\
\hline 27 & 0.007 & 3 & 2200 & 1000 & $\begin{array}{c}\text { CSNK2A2 (99.3) } \\
\text { CLK2 (97.6) } \\
\text { PHKG2 (95.6) }\end{array}$ & $\begin{array}{c}\text { CSNK2A2: } 240 \\
\text { CLK2: } 2995 \text { PHKG2: } \\
\text { >10,000 }\end{array}$ & $\begin{array}{c}\text { CAMK2A (84) } \\
\text { SGK1 (73) } \\
\text { CHEK2 (72) } \\
\text { BLK (67) } \\
\text { DAPK3 (66) } \\
\text { SGK3 (65) } \\
\text { DYRK2 (63) }\end{array}$ & $\begin{array}{c}\text { CAMK2A: }>10000 \\
\text { SGK1: } 3600 \\
\text { CHEK2: }>10000 \\
\text { BLK: }>10000 \\
\text { DAPK3: }>10000 \\
\text { SGK3: }>10000 \\
\text { DYRK2: } 720\end{array}$ \\
\hline 32 & 0.00 & $\mathbf{0}$ & NT & $>10000$ & $\begin{array}{c}\text { None }>90 \% \\
\text { CSNK2A2 (35) } \\
\text { CSNK2A1 (0) }\end{array}$ & $\begin{array}{l}\text { CSNK2A1: }>10000 \\
\text { CSNK2A2: }>10000\end{array}$ & & \\
\hline CX-4945 & 0.069 & 28 & NT & 45 & Figure S1 & NT & & \\
\hline
\end{tabular}

Table 3. Antiproliferative activity of pyrazolopyrimidines. ${ }^{13-16}$

$\begin{array}{ccc}\text { Cmpd } & \begin{array}{c}\text { Reported HCT- } \\ 116 \text { IC }\end{array} \text { (nM) } & \begin{array}{c}\text { Experimental HCT- } \\ 116 \text { IC } 50(\mathbf{n M})\end{array} \\ 17 & 10 & 33 \pm 9 \\ 15 & 30 & 63 \pm 23 \\ 18 & - & 31 \pm 9 \\ 16 & - & 510 \\ 19 & - & 1800 \pm 570 \\ 20 & - & >10000 \\ 22 & 81 & 150 \pm 22 \\ 24 & - & >10000 \\ 26 & - & >10000 \\ 27 & - & >10000 \\ 29 & 530 & 1800 \pm 250 \\ 31 & 3700 & >10000 \\ 32 & - & >10000 \\ \text { CX-4945 } & 2200 & >10000\end{array}$

subunits. Nine of the pyrazolopyrimidines demonstrated CSNK2A2 nanoBRET in cell target engagement IC $_{50}$ values less than or equal to $20 \mathrm{nM}$. CX-4945, for comparison, was shown to have a CSNK2A2 nanoBRET IC $_{50}=45 \mathrm{nM}$. We followed up on the off-targets for the subset of very selective compounds that inhibited 3 or fewer kinases. Follow-up was carried out in dose-response using an enzymatic and/or nanoBRET assay corresponding to each of the wild type off-target kinases inhibited $>60 \%$ in the DiscoverX scanMAX panel. Table 2 lists the kinases inhibited $>60 \%$ for $\mathbf{2 0}, \mathbf{2 4}, \mathbf{2 6}$, and $\mathbf{2 7}$. While the selectivity of all four analogs fit within probe criteria, ${ }^{19}$ the most potent compound in the CSNK2 nanoBRET assays (24) was chosen as the probe candidate. As shown in Table 2, DYRK2 was the only offtarget kinase to demonstrate an $\mathrm{IC}_{50}$ value $<1 \mu \mathrm{M}$. Of note, the potency of $\mathbf{2 4}$ in the CSNK2A1 and CSNK2A2 enzymatic assays was such that 100 - fold selectivity for CK2 over DYRK2, its most potently inhibited off-target kinase, was observed. Since it seemed to be a common off-target of compounds in our library, all analogs in Table 2 were tested in the DYRK2 nanoBRET assay. Only 17 was found to be active at $<1 \mu \mathrm{M}$ against DYRK2 in cells (Figure S3, IC $\mathrm{I}_{50}=160 \mathrm{nM}$ ). An $\mathrm{IC}_{50}$ value of $3.7 \mu \mathrm{M}$ was determined for $\mathbf{2 4}$ in the DYRK2 nanoBRET assay (Figure S3). The 100 -fold selectivity for CK2 over DYRK2 in the respective enzymatic assays was maintained in the cell-based system.

Given its modest CK2 activity in the nanoBRET assay, narrow selectivity profile, and structural similarly to 24,26 was chosen as a chemical starting point from which to synthesize a negative control. As shown in Scheme S4, 26 was globally methylated using methyl iodide, the various products were separated, 
and structural assignments made via spectroscopy. Compound 32 was profiled to determine both its kinome-wide selectivity and cellular target engagement of CSNK2A2. Based on no inhibition of any kinases $>80 \%$ at $1 \mu \mathrm{M}$ and no cellular activity in the CSNK2A2 nanoBRET assay up to $10 \mu \mathrm{M}, 32$ (SGC-CK2$1 \mathrm{~N}$ ) was chosen as the negative control: a structurally related compound that lacks CK2 affinity. In addition to a lack of cellular activity, 32 was also found to be devoid of CSNK2A1 and CSNK2A2 potency in the corresponding enzymatic assays.

Based upon reports that the previously exemplified pyrazolopyrimidines in our library inhibited the growth of HCT-116 cells and that 17 exhibited a high level of activity as a monotherapy in HCT-116 xenografts, ${ }^{15}$ we evaluated the antiproliferative activity of our entire library in this colon cancer cell line. Table 3 shows the previously reported cytotoxicity data in HCT-116 cells alongside the data we collected following $72 \mathrm{~h}$ treatment. Compounds that had previously been reported as cell growth inhibitors demonstrated antiproliferative activity in our hands as well. This was also true of the non-selective CK2 inhibitor CX-4945. ${ }^{12}$ Our new analogs $(18,19,20,24,26$, and 27) showed variable growth inhibition. Our negative control (32) did not demonstrate antiproliferative activity. Remarkably, the most selective compounds, 20, 24, 26, and 27, demonstrated no antiproliferative activity in this assay. Since these compounds were found to only inhibit CSNK2A1 and CSNK2A2, a working hypothesis is that the antiproliferative activity exhibited by less selective compounds was likely due to inhibition of an off-target kinase or combination of kinases and not due to inhibition of CK2.

Finally, we expanded our exploration of the antiproliferative activity of 24. CK2 inhibition has been linked with suppressing glioblastoma invasiveness as well as pro-survival signaling pathways and growth. ${ }^{20-21}$ As these studies employed U-87 MG cells, we tested the antiproliferative activity of $\mathbf{2 4}$ in this glioblastoma cell line after $72 \mathrm{~h}$ compound treatment. As was observed in HCT-116 cells, 24 demonstrated no antiproliferative activity when tested up to $10 \mu \mathrm{M}$. We also investigated whether 24 could activate caspase $3 / 7$ in U-87 MG cells. ${ }^{22}$ At multiple time points, no caspase $3 / 7$ activation was observed when tested up to $10 \mu \mathrm{M}$.

With so many putative substrates, $\mathrm{CK} 2$ is clearly a pleiotropic kinase. As such, CK2 inhibition is hypothesized to impact multiple pathways simultaneously, including several that drive cell growth and others that mediate apoptosis. Subcellular localization of CK2 has also been described as key to its function, adding another layer of complexity to $\mathrm{CK} 2$ biology. ${ }^{17}$ Additional studies are underway that aim to deconvolute CK2 biology using this new probe and the negative control.

We have described the design, synthesis, and biological evaluation of a series of pyrazolopyrimidines as selective dual inhibitors of CSNK2A1 and CSNK2A2. Compound 24 (SGC-CK21) emerged as our best probe candidate. This probe outperforms all published inhibitors in terms of kinome-wide selectivity. When combined with its potent cellular activity, our probe represents the best available tool to interrogate CK2 biology. Its lack of antiproliferative activity in our preliminary studies have motivated study of $\mathbf{2 4}$ in a broader panel of cancer cell lines. Supported by the high expression of CK2 in the brain and its implication in the molecular pathology of neurodegenerative diseases, the non-toxic nature of selective CK2 inhibitors supports that CK2 inhibition could be a viable approach for treating disorders of the brain.

\section{ASSOCIATED CONTENT}

\section{Supporting Information}

Supplemental material is available free of charge via the Internet at http://pubs.acs.org.

NanoBRET and antiproliferative assay details, experimental methods, synthesis and characterization of target compounds are included (PDF).

\section{AUTHOR INFORMATION}

\section{Corresponding Author}

* Tel: 919-962-5349. E-mail: alison.axtman@unc.edu.

\section{ORCID}

Carrow Wells: 0000-0003-4799-6792

David H. Drewry: 0000-0001-5973-5798

Julie E. Pickett: 0000-0002-9535-8528

Alison D. Axtman: 0000-0003-4779-9932

\section{Notes}

The authors declare no competing financial interest.

\section{Author Contributions}

$\perp$ C.W. and D.H.D. contributed equally to this work. The manuscript was written through contributions of all authors. All authors have given approval to the final version of the manuscript.

\section{Funding Sources}

The SGC is a registered charity (number 1097737) that receives funds from AbbVie, Bayer Pharma AG, Boehringer Ingelheim, Canada Foundation for Innovation, Eshelman Institute for Innovation, Genome Canada, Genentech, Innovative Medicines Initiative (EU/EFPIA) [ULTRA-DD grant no. 115766], Janssen, Merck KGaA Darmstadt Germany, MSD, Novartis Pharma AG, Ontario Ministry of Economic Development and Innovation, Pfizer, São Paulo Research Foundation-FAPESP, Takeda, and Wellcome $[106169 / Z Z 14 / Z]$. Research reported in this publication was supported in part by the NC Biotech Center Institutional Support Grant 2018-IDG-1030, and by the NIH 1U24DK11604.

\section{ACKNOWLEDGEMENT}

Constructs for NanoBRET measurements of CSNK2A1, CSNK2A2, and DYRK2 were kindly provided by Promega. Dr. Koshlap provided NMR support and helped with structural confirmation of 32. Dr. Ehrmann from the UNC Mass Spectrometry Core Laboratory provided HRMS support. Figure 1 was created with Biorender.com. We thank PharmAdvance for synthetic support.

\section{ABBREVIATIONS}

$\mathrm{nM}$, nanomolar; CK2, casein kinase 2; CSNK2A1/CK2 $\alpha$, casein kinase alpha 1; CSNK2A2/CK2 $\alpha^{\prime}$, casein kinase alpha 2; CK1, casein kinase 1; DYRK2, dual specificity tyrosine phosphorylation regulated kinase 2; TBB, 4,5,6,7-tetrabromobenzotriazole; BRET, bioluminescence resonance energy transfer; Nluc, Nanoluciferase; HEK-293, human embryonic kidney 293; HCT-116, human colon tumor 116; U-87 MG, Uppsala 87 malignant glioma 


\section{REFERENCES}

1. Ardito, F.; Giuliani, M.; Perrone, D.; Troiano, G.; Lo Muzio, L., The crucial role of protein phosphorylation in cell signaling and its use as targeted therapy. Int J Mol Med 2017, 40 (2), 271-280.

2. Plattner, F.; Bibb, J. A., Chapter 25 - Serine and Threonine Phosphorylation. In Basic Neurochemistry (Eighth Edition), Brady, S. T.; Siegel, G. J.; Albers, R. W.; Price, D. L., Eds. Academic Press: New York, 2012; pp 467-492.

3. Meggio, F.; Pinna, L. A., One-thousand-and-one substrates of protein kinase CK2? FASEB J 2003, 17 (3), 349-68.

4. Rabalski, A. J.; Gyenis, L.; Litchfield, D. W., Molecular Pathways: Emergence of Protein Kinase CK2 (CSNK2) as a Potential Target to Inhibit Survival and DNA Damage Response and Repair Pathways in Cancer Cells. Clin Cancer Res 2016, 22 (12), 2840-2847.

5. Nuñez de Villavicencio-Diaz, T.; Rabalski, A. J.; Litchfield, D. W., Protein Kinase CK2: Intricate Relationships within Regulatory Cellular Networks. Pharmaceuticals 2017, 10 (1), 27.

6. Ahmed, K.; Gerber, D. A.; Cochet, C., Joining the cell survival squad: an emerging role for protein kinase CK2. Trends Cell Biol 2002, 12 (5), 226-230.

7. Litchfield, D. W., Protein kinase CK2: structure, regulation and role in cellular decisions of life and death. Biochem J 2003, 369 (Pt 1), 1-15.

8. Szyszka, R.; Grankowski, N.; Felczak, K.; Shugar, D., Halogenated Benzimidazoles and Benzotriazoles as Selective Inhibitors of Protein-Kinases Ck-I and Ck-Ii from SaccharomycesCerevisiae and Other Sources. Biochem Biophys Res Comm 1995, 208 (1), 418-424.

9. Sarno, S.; Reddy, H.; Meggio, F.; Ruzzene, M.; Davies, S. P.; Donella-Deana, A.; Shugar, D.; Pinna, L. A., Selectivity of 4,5,6,7tetrabromobenzotriazole, an ATP site-directed inhibitor of protein kinase CK2 ('casein kinase-2'). FEBS Lett 2001, 496 (1), 44-48.

10. Pagano, M. A.; Bain, J.; Kazimierczuk, Z.; Sarno, S.; Ruzzene, M.; Di Maira, G.; Elliott, M.; Orzeszko, A.; Cozza, G.; Meggio, F.; Pinna, L. A., The selectivity of inhibitors of protein kinase CK2: an update. Biochem J 2008, 415 (3), 353-65.

11. Siddiqui-Jain, A.; Drygin, D.; Streiner, N.; Chua, P.; Pierre, F.; O'Brien, S. E.; Bliesath, J.; Omori, M.; Huser, N.; Ho, C.; Proffitt, C.; Schwaebe, M. K.; Ryckman, D. M.; Rice, W. G.; Anderes, K., CX4945 , an orally bioavailable selective inhibitor of protein kinase CK2, inhibits prosurvival and angiogenic signaling and exhibits antitumor efficacy. Cancer Res 2010, 70 (24), 10288-98.

12. Pierre, F.; Chua, P. C.; O'Brien, S. E.; Siddiqui-Jain, A.; Bourbon, P.; Haddach, M.; Michaux, J.; Nagasawa, J.; Schwaebe, M. K.; Stefan, E.; Vialettes, A.; Whitten, J. P.; Chen, T. K.; Darjania, L.; Stansfield, R.; Anderes, K.; Bliesath, J.; Drygin, D.; Ho, C.; Omori, M.; Proffitt, C.; Streiner, N.; Trent, K.; Rice, W. G.; Ryckman, D. M., Discovery and SAR of 5-(3-

chlorophenylamino)benzo[c] $[2,6]$ naphthyridine-8-carboxylic acid (CX-4945), the first clinical stage inhibitor of protein kinase CK2 for the treatment of cancer. J Med Chem 2011, 54 (2), 635-54.
13. Dowling, J. E.; Chuaqui, C.; Pontz, T. W.; Lyne, P. D.; Larsen, N. A.; Block, M. H.; Chen, H.; Su, N.; Wu, A.; Russell, D.; Pollard, H.; Lee, J. W.; Peng, B.; Thakur, K.; Ye, Q.; Zhang, T.; Brassil, P.; Racicot, V.; Bao, L.; Denz, C. R.; Cooke, E., Potent and Selective Inhibitors of CK2 Kinase Identified through Structure-Guided Hybridization. ACS Med Chem Lett 2012, 3 (4), 278-283.

14. Dowling, J. E.; Alimzhanov, M.; Bao, L.; Block, M. H.; Chuaqui, C.; Cooke, E. L.; Denz, C. R.; Hird, A.; Huang, S.; Larsen, N. A.; Peng, B.; Pontz, T. W.; Rivard-Costa, C.; Saeh, J. C.; Thakur, K.; Ye, Q.; Zhang, T.; Lyne, P. D., Structure and Property Based Design of Pyrazolo[1,5-a]pyrimidine Inhibitors of CK2 Kinase with Activity in Vivo. ACS Med Chem Lett 2013, 4 (8), 800-805.

15. Dowling, J. E.; Alimzhanov, M.; Bao, L.; Chuaqui, C.; Denz, C. R.; Jenkins, E.; Larsen, N. A.; Lyne, P. D.; Pontz, T.; Ye, Q.; Holdgate, G. A.; Snow, L.; O'Connell, N.; Ferguson, A. D., Potent and Selective CK2 Kinase Inhibitors with Effects on Wnt Pathway Signaling in Vivo. ACS Med Chem Lett 2016, 7 (3), 300-5.

16. Chuaqui, C. E.; Dowling, J. E.; Lyne, P.; Pontz, T.; Ye, Q. Preparation of cyanoarylaminocycloalkylaminopyrrolopyrimidine derivatives for use as antitumor agents. 2013; WO 2013144532A1.

17. Faust, M.; Montenarh, M., Subcellular localization of protein kinase CK2. A key to its function? Cell Tissue Res 2000, 301 (3), 32940.

18. Vasta, J. D.; Corona, C. R.; Wilkinson, J.; Zimprich, C. A.; Hartnett, J. R.; Ingold, M. R.; Zimmerman, K.; Machleidt, T.; Kirkland, T. A.; Huwiler, K. G.; Ohana, R. F.; Slater, M.; Otto, P.; Cong, M.; Wells, C. I.; Berger, B. T.; Hanke, T.; Glas, C.; Ding, K.; Drewry, D. H.; Huber, K. V. M.; Willson, T. M.; Knapp, S.; Muller, S.; Meisenheimer, P. L.; Fan, F.; Wood, K. V.; Robers, M. B., Quantitative, Wide-Spectrum Kinase Profiling in Live Cells for Assessing the Effect of Cellular ATP on Target Engagement. Cell Chem Biol 2017, 25 (2), 206-214.

19. Asquith, C. R. M.; Berger, B.-T.; Wan, J.; Bennett, J. M.; Capuzzi, S. J.; Crona, D. J.; Drewry, D. H.; East, M. P.; Elkins, J. M.; Fedorov, O.; Godoi, P. H.; Hunter, D. M.; Knapp, S.; Müller, S.; Torrice, C. D.; Wells, C. I.; Earp, H. S.; Willson, T. M.; Zuercher, W. J., SGC-GAK-1: A Chemical Probe for Cyclin G Associated Kinase (GAK). J Med Chem 2019, 62 (5), 2830-2836.

20. Pencheva, N.; de Gooijer, M. C.; Vis, D. J.; Wessels, L. F. A.; Wurdinger, T.; van Tellingen, O.; Bernards, R., Identification of a Druggable Pathway Controlling Glioblastoma Invasiveness. Cell Rep 2017, 20 (1), 48-60.

21. Zheng, Y.; McFarland, B. C.; Drygin, D.; Yu, H.; Bellis, S. L.; Kim, H.; Bredel, M.; Benveniste, E. N., Targeting Protein Kinase CK2 Suppresses Prosurvival Signaling Pathways and Growth of Glioblastoma. Clin Cancer Res 2013, 19 (23), 6484-6494.

22. Rahnel, H.; Viht, K.; Lavogina, D.; Mazina, O.; Haljasorg, T.; Enkvist, E.; Uri, A., A Selective Biligand Inhibitor of CK2 Increases Caspase-3 Activity in Cancer Cells and Inhibits Platelet Aggregation. ChemMedChem 2017, 12 (20), 1723-1736. 